\title{
O gênero Zygostates (Orchidaceae: Oncidiinae) no estado do Paraná, Brasil
} The genus Zygostates (Orchidaceae: Oncidiinae) in the state of Paraná, Brazil

\author{
Carla Adriane Royer ${ }^{1,4}$, A.L.V. Toscano de Brito $^{2}$ \& Eric de Camargo Smidt ${ }^{3}$
}

\begin{abstract}
Resumo
Zygostates consiste de ca. 26 espécies, das quais 15 ocorrem no Brasil. Através de consultas a herbários nacionais e estrangeiros, além da realização de trabalho de campo, oito espécies de Zygostates foram encontradas no Paraná: Zygostates alleniana, Z. bradei, Z. cornuta, Z. dasyrhiza, Z. lunata, Z. multiflora, $Z$. pellucida e Z. pustulata. O gênero é registrado para 36 dos 399 municípios paranaenses, principalmente na Floresta Ombrófila Densa e Floresta Ombrófila Mista, localizadas na Serra do Mar, Primeiro e Segundo Planaltos. De acordo com os critérios da IUCN, Z. alleniana, com ampla distribuição no estado, é a espécie de menor risco de extinção, enquanto Z. bradei, Z. pellucida e Z. multiflora, presentes somente em uma localidade, são as mais ameaçadas. Zygostates bradei encontra-se "Possivelmente Extinta" no estado; $Z$. pellucida e Z. multiflora foram avaliadas como "Criticamente em Perigo". São apresentados uma chave para identificação das espécies, descrições, ilustrações, lista de material examinado, dados sobre distribuição geográfica e estado de conservação dos táxons.
\end{abstract}

Palavras-chave: biodiversidade, flora do Paraná, IUCN, Mata Atlântica.

\begin{abstract}
Zygostates comprises ca. 26 species of which 15 occur in Brazil. Based on fieldwork and study of Brazilian and foreign herbaria eight species of Zygostates are recognized for Paraná: Zygostates alleniana, Z. bradei, Z. cornuta, Z. dasyrhiza, Z. lunata, Z. multiflora, Z. pellucida and Z. pustulata. The genus is recorded for 36 out of 399 municipalities, mostly inhabiting areas of Floresta Ombrófila Densa and Floresta Ombrófila Mista in Serra do Mar, Primeiro and Segundo Planaltos. Zygostates alleniana has low extinction risk according to IUCN criteria since it is distributed all over the state, while Z. bradei, Z. pellucida and Z. multiflora are found in only one locality, and, thus, they are the most threatened species. Zygostates bradei is "Possibly Extinct" locally; Z. pellucida and Z. multiflora are "Critically Endangered". A key for species identification, descriptions, illustrations, list of specimens examined, distribution maps and conservation status for all taxa are herein provided.
\end{abstract}

Key words: biodiversity, Paraná flora, IUCN, Atlantic Forest.

\section{Introdução}

Com cerca de 26 espécies (Toscano de Brito, em preparação), o gênero Zygostates Lindl. apresenta distribuição disjunta entre a Mata Atlântica e o norte da América do Sul (Chase \& Toscano de Brito 2009; Sambin \& Chiron 2015). Dentre as espécies aceitas até o momento, 15 ocorrem no Brasil, todas endêmicas do bioma Mata
Atlântica (Royer et al. 2017). O gênero pertence à subfamília Epidendroideae, tribo Cymbidieae, subtribo Oncidiinae (Chase et al. 2015).

Zygostates foi descrito por Lindley (1837), baseando-se em duas espécies: Zygostates cornuta Lindl., selecionada como lectótipo por Toscano de Brito (2001), e Zygostates lunata Lindl. No estado do Paraná, o gênero foi citado pela primeira vez

\footnotetext{
${ }^{1}$ Universidade Estadual Paulista “Júlio de Mesquita Filho" - UNESP, Inst. Biociências, Depto. Botânica, Av. 24A 1515, 13506-900, Rio Claro, SP, Brasil. ${ }^{2}$ Harvard University Herbaria, Associate, Oakes Ames Orchid Herbarium, Marie Selby Botanical Gardens, 811 South Palm Avenue, Sarasota, FL 34236 , Estados Unidos.

${ }^{3}$ Universidade Federal do Paraná, Setor de Ciências Biológicas, Centro Politécnico, Jardim da Américas, 81531-980, Curitiba, PR, Brasil.

${ }^{4}$ Autor para correspondência: carladriane@gmail.com
} 
por Kräenzlin (1911). Três espécies são citadas por esse autor: Z. lunata, Z. dasyrhiza (Kräenzl.) Schltr. (como Ornithocephalus dasyrhizus Kräenzl.) e Z. pustulata (Kräenzl.) Schltr. (como O. pustulatus Kräenzl.). Pabst \& Dungs (1977) listam sete espécies de Zygostates para o estado: Z. alleniana Kräenzl., Z. bradei (Schltr.) Garay (como Dipteranthus), Z. dasyrhiza, Z. lunata, Z. multiflora (Rolfe) Schltr., Z. papillosa Cogn. (= Z. alleniana) e Z. pustulata. Recentemente, Smidt (2014) catalogou o mesmo número de espécies, acrescentando $Z$. cornuta à lista anterior. Esses mesmos táxons foram também considerados presentes para o estado por BFG (2015).

Este trabalho tem como objetivo elaborar a monografia do gênero Zygostates para o estado do Paraná, incluindo chave de identificação das espécies, descrições, ilustrações, lista de material estudado, dados sobre a distribuição e estado de conservação dos táxons.

\section{Material e Métodos}

Análises morfológicas foram realizadas baseando-se em exsicatas depositadas nos herbários AMES, B, C, CESJ, EFC, F, FUEL, HB, HCF, HRCB, HUEFS, HUEM, K, MBM, MO, NY, PACA, R, RB, S, SP, UPCB e US (acrônimos segundo Thiers, continuamente atualizado), e complementadas com materiais coletados no campo, principalmente em Floresta Ombrófila Densa e Floresta Ombrófila Mista. A terminologia morfológica adotada foi baseada em Toscano de Brito (2001) e Stern (2004). As descrições foram padronizadas utilizando-se o programa DELTA (Dallwitz et al. 2011). Os sinônimos aceitos neste trabalho estão de acordo com Toscano de Brito (2001). As ilustrações foram organizadas em pranchas de acordo com a similaridade morfológica entre as espécies.

A distribuição geográfica dos táxons no estado do Paraná foi mapeada em imagem delimitada por quadrículas de $1^{\circ} \times 1^{\circ}$ através do programa DIVA-GIS 7.5 (Hijmans et al. 2012). O estado de conservação local de cada táxon foi inferido seguindo as recomendações do sistema IUCN (2001), considerando-se o número de localidades, a área, extensão e a qualidade do habitat. A extensão de ocorrência (EOO) e a área de ocupação (AOO) foram obtidas utilizando-se o software GeoCAT (Geospatial Conservation Assessment Tool - Bachman et al. 2011).

A descrição do habitat ocupado pelas espécies foi baseada nas cinco regiões ou zonas de paisagens naturais reconhecidas para o estado (Maack 1968): Litoral, Serra do Mar, Primeiro, Segundo e Terceiro Planaltos. Nestas são encontrados cinco tipos de vegetação (Veloso et al. 1991; Roderjan et al. 1993): 1. Floresta Ombrófila Densa, no Litoral e Serra do Mar, com os subtipos de floresta Altomontana (acima de $1200 \mathrm{~m}$ ), Montana (600-1200 m), Submontana (20-600 m) e de Terras Baixas (até $20 \mathrm{~m}$ ), além de formações associadas (refúgios ou campos de altitude, formações pioneiras ou restinga e mangue); 2. Floresta Ombrófila Mista, nas regiões mais altas ao sul da região planaltina; 3. Estepe Ombrófila (Campos Gerais) nas mesmas regiões; 4. Floresta Estacional Semidecidual Subxérica, norte e oeste do Segundo e Terceiro Planaltos; 5. Savana Estacional Subxérica (Cerrado), no nordeste do estado.

\section{Resultados e Discussão}

Foram analisados 89 materiais coletados em 36 municípios do estado, todos inseridos no bioma Mata Atlântica, e 12 exsicatas provenientes de outros estados, citados como material adicional examinado. Foram reconhecidas para o Paraná: Zygostates alleniana, Z. bradei, Z. cornuta, Z. dasyrhiza, Z. lunata, Z. multiflora, Z. pustulata e Z. pellucida Rchb.f., esta última citada pela primeira vez para para o Paraná por Blum et al. (2011). Com um total de oito espécies ocorrentes, o estado passa a ser considerado o mais rico em espécies no Brasil. Segundo Royer et al. (2017), o estado do Rio de Janeiro, com sete espécies, se trata do segundo mais rico, seguido do Espírito Santo, São Paulo e Santa Catarina, todos com seis espécies cada.

No Brasil, Zygostates encontra-se restrito à Mata Atlântica, bioma sob constante pressão antrópica e historicamente ameaçado. $\mathrm{Na}$ lista vermelha de plantas ameaçadas de extinção do Paraná (Hatschbach \& Ziller 1995), nenhuma espécie foi relatada como rara, em perigo ou vulnerável. Porém o presente estudo identificou espécies com poucos registros e localizados em áreas bastante reduzidas, fato que as enquadra nas categorias "Espécie em Perigo", "Criticamente em Perigo" e "Possivelmente Extinta" segundo os índices da IUCN (2001).

A maior riqueza de espécies é encontrada na Serra do Mar, Primeiro e Segundo Planaltos, principalmente na Floresta Ombrófila Densa com um total de seis espécies, incluindo aquelas com somente um registro para o estado, e a Floresta Ombrófila Mista com cinco espécies. Assim como observado em outras regiões, a riqueza presente no 
leste paranaense pode ser influenciada pelo esforço de coleta, já que um dos maiores herbários e centros de pesquisa do estado localizam-se nessa região. Outro fato a ser destacado é da região possuir a maior área de Floresta Atlântica do Brasil devido principalmente as altas escarpas da Serra do Mar, o relevo acidentado e o solo de baixa fertilidade agrícola que dificultaram o avanço antrópico na região (Lange 1997).

1. Zygostates Lindl., Edwards's Bot. Reg. 23: t.1927 (1837). LECTÓTIPO: Zygostates cornuta Lindl., selecionado por Toscano de Brito (2001).

Plantas epífitas, simpodiais, eretas ou pendentes. Raízes cespitosas ou distribuídas ao longo do caule, glabras ou pilosas. Caule inconspícuo ou alongado, às vezes ramificado, geralmente coberto pelas bainhas das folhas laterais, a região apical entumecida em pseudobulbo. Pseudobulbos uni ou bifoliados, glabros, raramente papilosos, pequenos, ovoides, elipsoides ou fusiformes, sulcados ou lisos, aglomerados ou raramente distribuídos ao longo do caule. Folhas laterais alternas, verdes à verde-acinzentadas, inconspícuamente à distintamente pecioladas, invaginantes, articuladas, bifaciais, planas a conduplicadas, coriáceas ou carnosas, lanceoladas, espatuladas ou elípticas, glabras, raramente papilosas, usualmente quilhadas abaxialmente e às vezes sulcadas adaxialmente, geralmente torcidas, ápice agudo a obtuso. Folhas apicais similares às laterais, desprovidas de bainhas, inconspícuamente pecioladas e articuladas com o pseudobulbo. Inflorescência racemosa, lateral, emergindo da base do pseudobulbo, ereta ou arqueada, distintamente pedunculada; eixo da inflorescência torcido, glabro, raro papiloso, coberto por brácteas. Flores simétricas, raramente assimétricas, geralmente ressupinadas, pedicelo frequentemente curvado no ápice. Sépala dorsal reflexa ou patente, obovada, oblonga, elíptica ou espatulada, livre ou minimamente conada na base com as sépalas laterais, margens inteiras. Sépalas laterais reflexas ou patentes, oblongas à ovadas, espatuladas, às vezes falciformes, livres ou levemente conadas na base, margens inteiras. Pétalas patentes, às vezes inflexas, unguiculadas, obovadas, espatuladas ou elípticas, planas ou convexas, raro densamente glandular ou carenada na face adaxial, ápice agudo ou obtuso, margens retas ou recurvadas, inteiras ou irregulares. Labelo inteiro, raramente bilobado na base, inflexo, reflexo ou patente, ovado, ovado-lanceolado, oblongo, subquadrado, panduriforme ou sacado, côncavo, usualmente quilhado na face abaxial e às vezes na face adaxial, ápice agudo, margens retas ou recurvadas, inteiras ou irregulares; disco provido de calosidade glandular-tricomatosa, de cores e formas variadas. Coluna sigmoide, provida de dois apêndices basais ou laterais ao redor da cavidade estigmática, raramente ausentes; cavidade estigmática conspícua, oblonga, ovada ou elíptica; rostelo conspícuo, geralmente ultrapassando em comprimento o restante da coluna, variável na forma, curvado ou projetado para frente; antera muito mais curta ou quase tão longa quanto o rostelo, o ápice curto ou longo-rostrado, as margens laterais geralmente providas de um dente inconspícuo próximo ao $1 / 3$ basal ou região mediana; polínias 4, em pares superpostos, ovoides ou globosas; estipe longo e estreito, usualmente dilatado próximo à área de inserção das polínias; viscídio dorsal, ovado, elíptico, arredondado ou unciforme. Frutos pedicelados, subglobosos, carenados e angular em seção transversal.

\section{Chave de identificação das espécies de Zygostates ocorrentes no estado do Paraná}

1. Raízes pilosas, ápice da coluna com margem fortemente dentada ou lacerada

1'. Raízes glabras, ápice da coluna com margem inteira.

2. Pétalas densamente glandular-tricomatosas na face adaxial, fortemente convexas, às vezes quase tubulares, projetadas para frente e para baixo.................................... 1.7. Zygostates pellucida

2'. Pétalas glabras, patentes ou levemente curvadas para frente, côncavas, planas ou levemente convexas.

3. Coluna desprovida de apêndices ..... 1.8. Zygostates pustulata

3'. Coluna provida de apêndices basais ou laterais ao redor da cavidade estigmática.

4. Labelo com margem dentada ou fimbriada.

5. Calo do labelo apiculado na base e bilobado no ápice; rostelo provido abaxialmente de uma aba truncada, levemente crenada ou bilobada .........1.5. Zygostates lunata 
5'. Calo do labelo truncado na base, o ápice inteiro e abaxialmente sulcado; rostelo desprovido de aba abaxial...... 1.3. Zygostates cornuta.

4'. Labelo com margem inteira.

6. Flores assimétricas; pétalas carenadas na face adaxial 1.2. Zygostates bradei

6'. Flores simétricas; pétalas adaxialmente lisas.

7. Labelo distintamente sacado, calosidade do labelo rasa, base cordada e bilobada e ápice inteiro 1.1. Zygostates alleniana

7'. Labelo levemente panduriforme quando explanado, giboso na região mediana, calosidade do labelo carnosa, arredondada, base inteira e ápice emarginado. 1.6. Zygostates multiflora

1.1. Zygostates alleniana Kräenzl. Notizbl. Königl., Bot. Gart. Berlin. 2: 55. 1898.

= Dipteranthus lindmanii Kräenzl. Kongl. Svenska Vetensk. Acad. Handl. 46: 80. 1911.

= Zygostates lindmanii (Kräenzl.) Schltr. Repert. Spec. Nov. Regni Veg. Beih. 16: 449. 1920.

= Zygostates aquinoi Schltr. Repert. Spec. Nov. Regni Veg. Beih. 35: 105. 1925.

= Zygostates papillosa Cogn. Bull. Soc. Roy. Bot. Belgique 43: 333. 1907.

Fig. 1a-h

Planta 37-59 mm alt., ereta. Raízes cespitosas, glabras. Pseudobulbos 2,8-3,6 × 1,6-2 mm, uni ou bifoliados, glabros, ovoides a subglobosos, lisos, congestos, parcialmente cobertos pelas bainhas das folhas laterais. Folhas laterais $18-30 \times$ $1,9-4,3 \mathrm{~mm}$, verdes, carnosas, lanceoladas, glabras, abaxialmente quilhadas e um pouco torcidas, ápice agudo a obtuso. Folhas apicais similares às laterais, $17-34 \times 2,2-4,1 \mathrm{~mm}$. Inflorescência 33-50 $\mathrm{mm}$ compr., ereta ou arqueada; brácteas 1,4-4 $\times$ $0,6-1,5 \mathrm{~mm}$, laxas, ovadas à lanceoladas, glabras, côncavas, abaxialmente quilhadas. Flores simétricas, ressupinadas. Sépala dorsal 2,9-4 × 1,2-1,8 mm, branca, reflexa ou patente, espatulada, côncava, abaxialmente quilhada, ápice obtuso, margens inteiras. Sépalas laterais 2,8-3,9 × 1,6-1,9 mm, brancas, reflexas ou patentes, ovadas, côncavas, ápice agudo ou obtuso, margens inteiras. Pétalas 2,9$4,3 \times 2,1-3,7 \mathrm{~mm}$, brancas, patentes, unguiculadas, levemente convexas, glabras, ápice obtuso, margens erosas. Labelo 2,8-4,2 × 2-3,2 mm, branco, inflexo, sacado, côncavo, abaxialmente quilhado, ápice agudo, margens inteiras; disco com calosidade verde, rasa, cuneiforme, levemente côncava, glandular-tricomatosa, a base cordada e bilobada. Coluna 2,5-3,7 mm compr., sigmoide, curvada em direção ao ápice, provida na base de dois apêndices laterais eretos, triangulares, verde-claros; cavidade estigmática conspícua, ovada; rostelo recurvado; ápice da coluna com margem inteira; antera com âmbito claviforme, distintamente rostrada, aguda a subaguda, as margens laterais providas de um dente inconspícuo em cada lado próximo ao terço basal; polinário com viscídio ovado.

Material examinado: Campo Mourão, Parque Municipal do Lago, 21.IX.2004, fl., E.G. Paulino 54 (HCF, MBM); Capela do Calvário, 5.XI.2005, fl., H.C.L. Geraldino 275 (HCF). Curitiba, s.d., fl., F. Lange 8512 (MBM); Pinheirinho, XII.1970, fl., M. Leinig 461 (HB). Foz do Iguaçu, Parque Nacional do Iguaçu, 12.X.2009, fl., L.G. Temponi et al. 694 (MBM). Guaíra, Sete Quedas, 14.XI.1963, fl., E. Pereira \& G. Hatschbach 7889 (HB). Maringá, Orquidário UEM - Campus UEM, 16.IX.2005, fl., A.M. Janunzzi 137 (HUEM). Palmeira, Colônia Quero-Quero, 10.II.1951, fl., G. Hatschbach 2722 (MBM, HB). Pitanga, Borboleta, 13.XII.1973, fl., G. Hatschbach 33506 (MBM). Planaltina do Paraná, 17.IX.1969, fl., G. Hatschbach 22196 (C, MBM). Ponta Grossa, Buraco do Padre, 24.X.1989, fl., J.M. Silva et al. 729 (MBM). Ribeirão do Pinhal, Salto Laranjinha, 4.XI.1999, fl., $J$. Carneiro 800 (MBM). São João do Triunfo, 7.XI.1967, fl., G. Hatschbach 17735 (HB, MBM). São José dos Pinhais, Cultivado em orquidário, 17.XII.2014, fl., C.A. Royer 56 (UPCB). Serrinha, 9.XII.1908, P.K.H. Dusén $7333 b$ - misturada com espécimes de Z. dasyrhiza (AMES, HB, NY, S).

Zygostates alleniana é encontrada por quase toda a extensão territorial paranaense, desde o Primeiro ao Terceiro Planaltos, habitando as Florestas Ombrófila Mista, Estacional Semidecidual e Estepe Gramíneo Lenhosa. Ocorre também nos estados do Rio Grande do Sul, Santa Catarina e São Paulo (Royer et al. 2017), na Argentina (Johnson 2001) e no Paraguai (Toscano de Brito 1994).

Segundo os critérios da IUCN (2001), esta espécie se enquadra na categoria "Pouco Preocupante" (LC; B1b(i,ii)). Encontrada em todos os biomas do estado, apresenta uma extensa área de ocorrência (EOO) e ocupação (AOO). Além disso, ocorre em dois parques nacionais (PARNA): PARNA Iguaçu e PARNA dos Campos Gerais.

Zygostates alleniana assemelha-se à $Z$. multiflora, mas difere dessa através do labelo sacado, abaxialmente quilhado e sua calosidade rasa e cuneiforme. Floresce entre setembro e dezembro. 

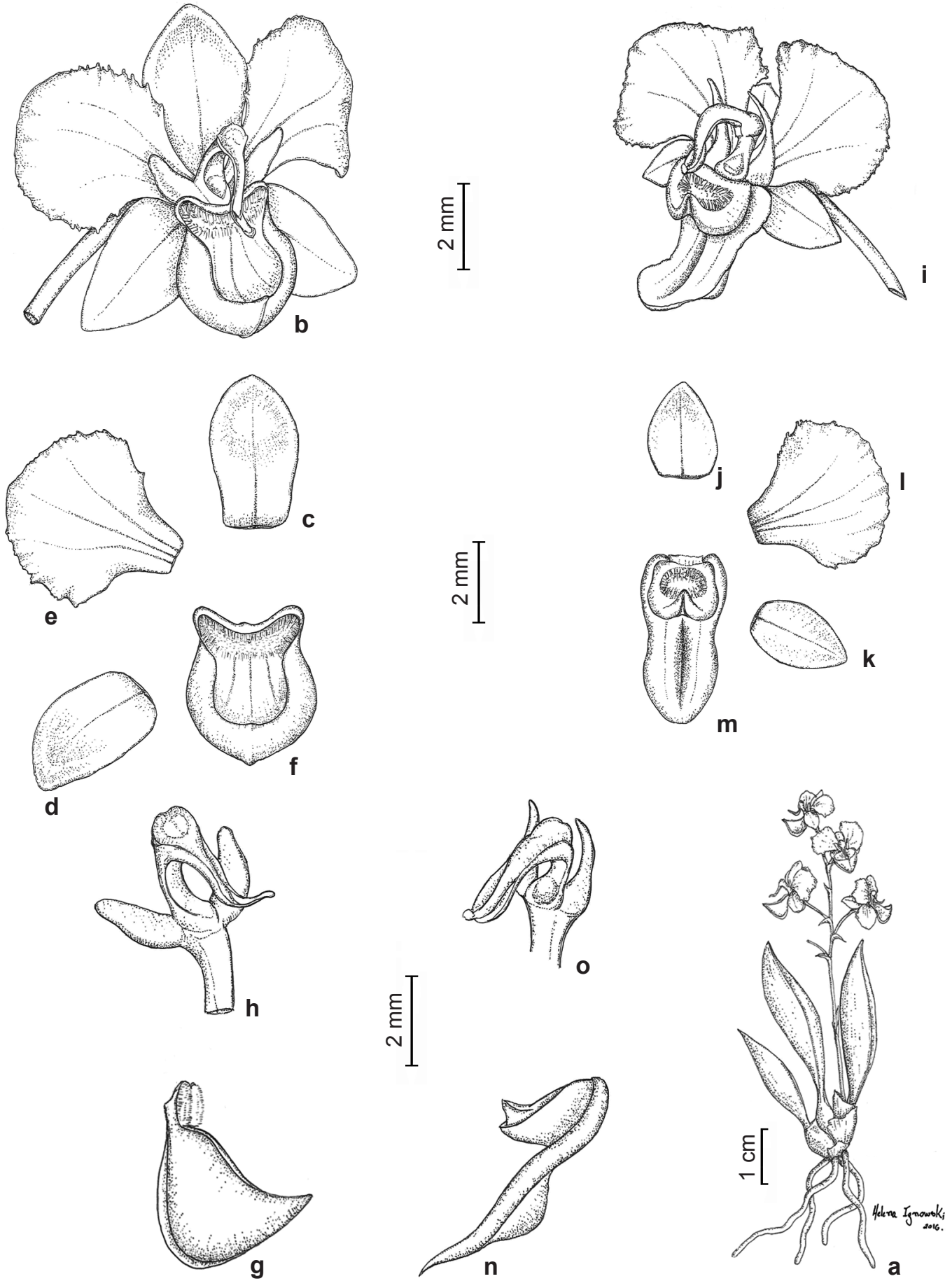

Figura 1 - a-h. Zygostates alleniana - a. hábito; b. flor; c. sépala dorsal, vista frontal; d. sépala lateral, vista frontal; e. pétala, vista frontal; f. labelo, vista frontal; g. labelo, vista lateral; h. coluna, vista frontal. i-n. Z. multiflora - i. flor; j. sépala dorsal, vista frontal; $\mathrm{k}$. sépala lateral, vista frontal; 1. pétala, vista frontal; m. labelo, vista frontal; $\mathrm{n}$. labelo, vista lateral; o. coluna, vista frontal. (a-h. C.A. Royer 56; o. J. Cordeiro \& J.M. Silva 234).

Figure 1 - a-h. Zygostates alleniana - a. habit; b. flower; c. dorsal sepal, frontal view; d. lateral sepal, frontal view; e. petal, frontal view; f. lip, frontal view; g. lip, lateral view; h. column, frontal view. i-n. Z. multiflora -i. flower; j. dorsal sepal, frontal view; k. lateral sepal, frontal view; 1. petal, frontal view; m. lip, frontal view; n. lip, lateral view; o. column, frontal view. (a-h. C.A. Royer 56; o. J. Cordeiro \& J.M. Silva 234). 
1.2. Zygostates bradei (Schltr.) Garay, Bot. Mus. Leafl. 21: 263. 1967.

= Dipteranthus bradei Schltr. Anexos Mem. Inst. Butantan, Secc. Bot. 1(4): 65. 1922.

=Dipteranthus duchii Pabst. Bradea. 1(8): 56. 1971.

$=$ Zygostates rotundiglossa Pabst. An. 14 Congr. Soc. Bot. Bras.: 21. 1964.

Fig. 2a-g

Planta ca. 73,5 mm alt., pendente. Raízes cespitosas, glabras. Pseudobulbos ca. 2,8 $\times 1,6$ $\mathrm{mm}$, unifoliados, glabros, ovoides, lisos, congestos, parcialmente cobertos pelas bainhas das folhas laterais. Folhas laterais ca. 35,3 × 5,7 mm, verdes, carnosas, lanceoladas a espatuladas, glabras, abaxialmente quilhadas, sulcadas adaxialmente, torcidas, ápice agudo. Folha apical similar às laterais, ca. 11,5 × 3,5 mm. Inflorescência ca. $70 \mathrm{~mm}$ compr., ereta ou arqueada; brácteas 2,3$2-8 \times 0,9-1 \mathrm{~mm}$, laxas, ovadas a lanceoladas, glabras, côncavas, abaxialmente quilhadas. Flores assimétricas, ressupinadas. Sépala dorsal ca. 3 $\times 1,9 \mathrm{~mm}$, verde, reflexa, espatulada a obovada, côncava, abaxialmente quilhada, ápice obtuso, margens levemente irregulares. Sépalas laterais ca. $6 \times 2,2 \mathrm{~mm}$, verdes, reflexas, espatuladas, côncavas, abaxialmente quilhadas, ápice obtuso, margens levemente irregulares. Pétalas ca. $2,8 \times 1,6 \mathrm{~mm}$, brancas a levemente esverdeadas, curvadas para frente, obovadas, convexas, glabras, carenadas na face adaxial, ápice obtuso, margens levemente irregulares. Labelo ca. $3 \times 3 \mathrm{~mm}$, branco, reflexo, subquadrado, ligeiramente convexo, adaxialmente quilhado, ápice agudo, margens inteiras; disco com calosidade amarela, sublunada, côncava, glandulartricomatosa. Coluna ca. $2 \mathrm{~mm}$ compr., fortemente recurvada em direção ao ápice, provida de dois apêndices laterais triangulares, verdes com ápice amarelo; cavidade estigmática conspícua, raro inconspícua, elíptica; rostelo recurvado, torcido e voltado para direita ou para esquerda; ápice da coluna com margem inteira; antera estreitamente ovada, distintamente rostrada, aguda, muita mais curta do que o rostelo, as margens laterais providas de um dente inconspícuo em cada lado próximo à região mediana; polinário com viscídio escuro, arredondado, torcido, apiculado, distintamente unciforme.

Material examinado: Guaratuba, Rio da Divisa, 11.II.1962, fl., G. Hatschbach 9820 (B, MBM).

Material adicional examinado: BRASIL. SANTA CATARINA: Cultivada no orquidário Seidel, 9.XI.2015, fl., C.A. Royer 58 (UPCB).

Zygostates bradei possui registro somente para o litoral paranaense. Ocorre também nos estados de Santa Catarina, São Paulo, Alagoas e Pernambuco (Royer et al. 2017).
Segundo os critérios da IUCN (2001), Z. bradei deve ser enquadrada na categoria "Possivelmente Extinta" para o estado (VU; D2 CR), uma vez que possui somente um registro fora de unidade de conservação e foi coletado há mais de 50 anos.

Zygostates bradei é reconhecida através da forma das sépalas laterais, que são visivelmente maiores que o restante das peças florais, pela morfologia das pétalas, as quais são providas de uma calosidade em forma de "V" na face adaxial, mais ou menos na metade da lâmina, pelo labelo fortemente recurvado e pela assimetria de suas flores, sobretudo o rostelo torcido e o viscídio unciforme. Floresce em fevereiro.

1.3. Zygostates cornuta Lindl. Edwards's Bot. Reg. 23: t.1927 (1837).

$=$ Zygostates chateaubriandii Ruschi. Bol. Mus. Biol. Prof. Mello Leitão 16: 1. 1955.

$=$ Zygostates lunata var. subintegripetala Cogn. $\mathrm{Fl}$. Bras. 3(6): 218. 1905.

Fig. 3j-q

Planta $88-233 \mathrm{~mm}$ alt., geralmente pendente. Raízes cespitosas, glabras. Pseudobulbos 4,6-11,6 $\times 1,5-3,2 \mathrm{~mm}$, unifoliados, glabros, ovoides a elipsoides, lateralmente sulcados, congestos, parcialmente cobertos pelas bainhas das folhas laterais. Folhas laterais 53,4-64,2 × 5-10,1 mm, verdes, coriáceas, lanceoladas, espatuladas ou elípticas, glabras, abaxialmente quilhadas e um pouco torcidas, ápice agudo a obtuso. Folhas apicais similares às laterais, $29,9-72,6 \times 6,1-10,8 \mathrm{~mm}$. Inflorescência 83,2-125 mm compr., arqueada; brácteas 1,8-3,3 × 0,6-1,2 mm, laxas, lanceoladas, ovadas ou triangulares, glabras, côncavas. Flores simétricas, ressupinadas. Sépala dorsal 3,4-4,2 $\times$ 1,4-2 mm, amarelo-clara, reflexa, elíptica, plana, abaxialmente quilhada, ápice agudo a obtuso, margens inteiras. Sépalas laterais 3,3-4 × 1,7-2,5 $\mathrm{mm}$, amarelo-claras, reflexas, ovadas, falciformes, convexas, abaxialmente quilhadas, ápice obtuso, margens inteiras. Pétalas 3,7-4,6 × 3,8-5 mm, alaranjadas, eretas, unguiculadas, reflexas em direção ao ápice, planas, glabras, ápice obtuso, margens fimbriadas. Labelo $4-5,1 \times 1,1-1,5 \mathrm{~mm}$, branco a esverdeado, inflexo, oblongo, côncavo, ápice agudo, margens dentadas ou fimbriadas; disco com calosidade amarelo-marrom, côncava, base truncada e pilosa, ápice inteiro, papiloso, abaxialmente sulcado. Coluna 2-3,7 mm compr., sigmóide, provida na base de dois apêndices laterais claviformes, amarelos ou alaranjados; cavidade estigmática conspícua, ovada a elíptica; rostelo curvado para cima em direção ao ápice; ápice da coluna com margem inteira; antera 
operculada, ovada, distintamente rostrada, as margens laterais providas de um dente inconspícuo em cada lado próximo à região mediana; polinário com viscídio ovado.

Material examinado: Antonina, 27.II.1965, fl., $G$. Hatschbach 13910 (MBM); Rio Manduira, 11.II.1981, fl., G. Hatschbach 43583 (MBM, MO); Rio Faisqueira, 7.I.1986, fl., R. Kummrow et al. 2708 (MBM); Porto Limoeiro, 26.II.1997, fl., G. Tiepolo \& R.M. Britez 735 (EFC). Cerro Azul, Turvo, 11.II.1960, fl., G. Hatschbach 6741 (HB, MBM); Barra do Canha, 18.II.1982, fl., G. Hatschbach 43610 (MBM). Curitiba, I.2010, fl., E.C. Smidt 972 (UPCB). Doutor Ulysses, Rio

Turvo, 19.IV.2006, fl., E. Barbosa \& E.F. Costa 1259 (MBM). Guaraqueçaba, Rio do Cedro, 8.III.1968, fl., G. Hatschbach 18676 (MBM, HB). Guaratuba, Porto Miranda, Rio São João, 26.II.1968, fl., G. Hatschbach 18640 (C, HB, MBM, US); Descampado, 15.I.1994, fl., G. Hatschbach \& J.M. Silva 58811 (MBM); Rio Cubatão, Ilha do Furado, 2.II.2000, fl., M. Borgo et al. 590 (MBM); Rio São João, 4.II.2012, fl., M.G. Caxambu et al. 3790 (HCF). Morretes, Colônia Floresta, 23.I.1969, fl., G. Hatschbach \& C. Koczicki 20870 (HB, MBM). Paranaguá, Serra da Prata, 21.III.1910, fl., P.K.H. Dusén 9856 (S); 5.III.1911, fl., P.K.H. Dusén 11584 (S); 28.I.1963, fl., G. Hatschbach 9880 (B, MBM); Morro do Inglês, 18.II.1976, fl., G. Hatschbach 38106 (MBM); Ilha do Mel, Praia da
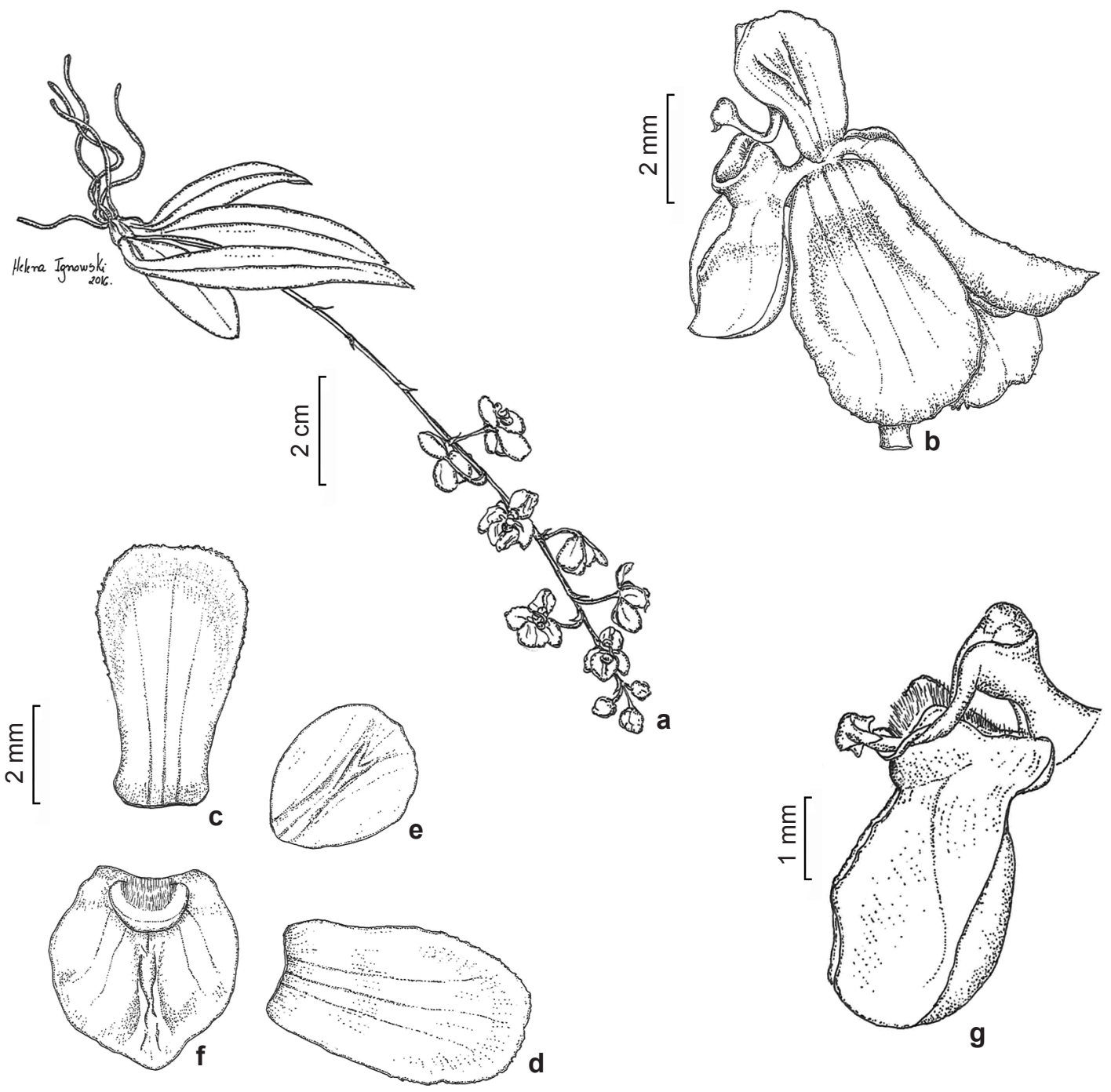

Figura 2 -a-g. Zygostates bradei - a. hábito; b. flor; c. sépala dorsal, vista frontal; d. sépala lateral, vista frontal; e. pétala, vista frontal; f. labelo, vista frontal; g. labelo e coluna, vista lateral (C.A. Royer 58).

Figure 2 - a-g. Zygostates bradei - a. habit; b. flower; c. dorsal sepal, frontal view; d. lateral sepal, frontal view; e. petal, frontal view; f. lip, frontal view; g. lip and column, lateral view (C.A. Royer 58).

Rodriguésia 68(4): 1431-1446. 2017 
Fortaleza, 10.XII.1996, fl., R.B. Singer (MBM 226960); Estação Biológica da Ilha do Mel, 27.I.1998, fl., S.M. Silva (UPCB 49568). São José dos Pinhais, Castelhanos, 7.II.1998, fl., J.M. Silva et al. 2266 (CESJ, HUEFS, MBM). S. loc., 30.IV.1979, fl., S. Birk 22 (HB); 19081916, fl., Dusén (S).

Zygostates cornuta é encontrada no Litoral, Serra do Mar, Primeiro e Segundo Planaltos, habitando as Florestas Ombrófilas Densa e Mista e Estepe Gramíneo Lenhosa. Ocorre ao longo da Mata Atlântica abrangendo além do Paraná, os estados de Santa Catarina, São Paulo, Rio de Janeiro, Minas Gerais, Espírito Santo e Bahia (Royer et al. 2017).

Segundo os critérios da IUCN (2001), esta espécie enquadra-se na categoria "Quase Ameaçada" (NT; B1b(i,ii)). A restrita área de ocorrência (EOO) e de ocupação (AOO) indicam uma possível transferência futura deste táxon para a categoria "Vulnerável". Ocorre em dois parques nacionais do estado: PARNA da Ilha do Mel e PARNA Saint Hilaire/Lange, além da área de proteção ambiental de Guaraqueçaba (APA Guaraqueçaba).

Zygostates cornuta e Z. lunata são espécies muito próximas e comumente confundidas. Vegetativamente são indistinguíveis, porém $Z$. cornuta difere de $Z$. lunata pela forma do calo do labelo (truncado na base, com o ápice inteiro e abaxialmente sulcado vs. apiculado na base e bilobado no ápice) e morfologia da coluna, sobretudo pela ausência de uma membrana na face abaxial do rostelo. Floresce de dezembro a abril.
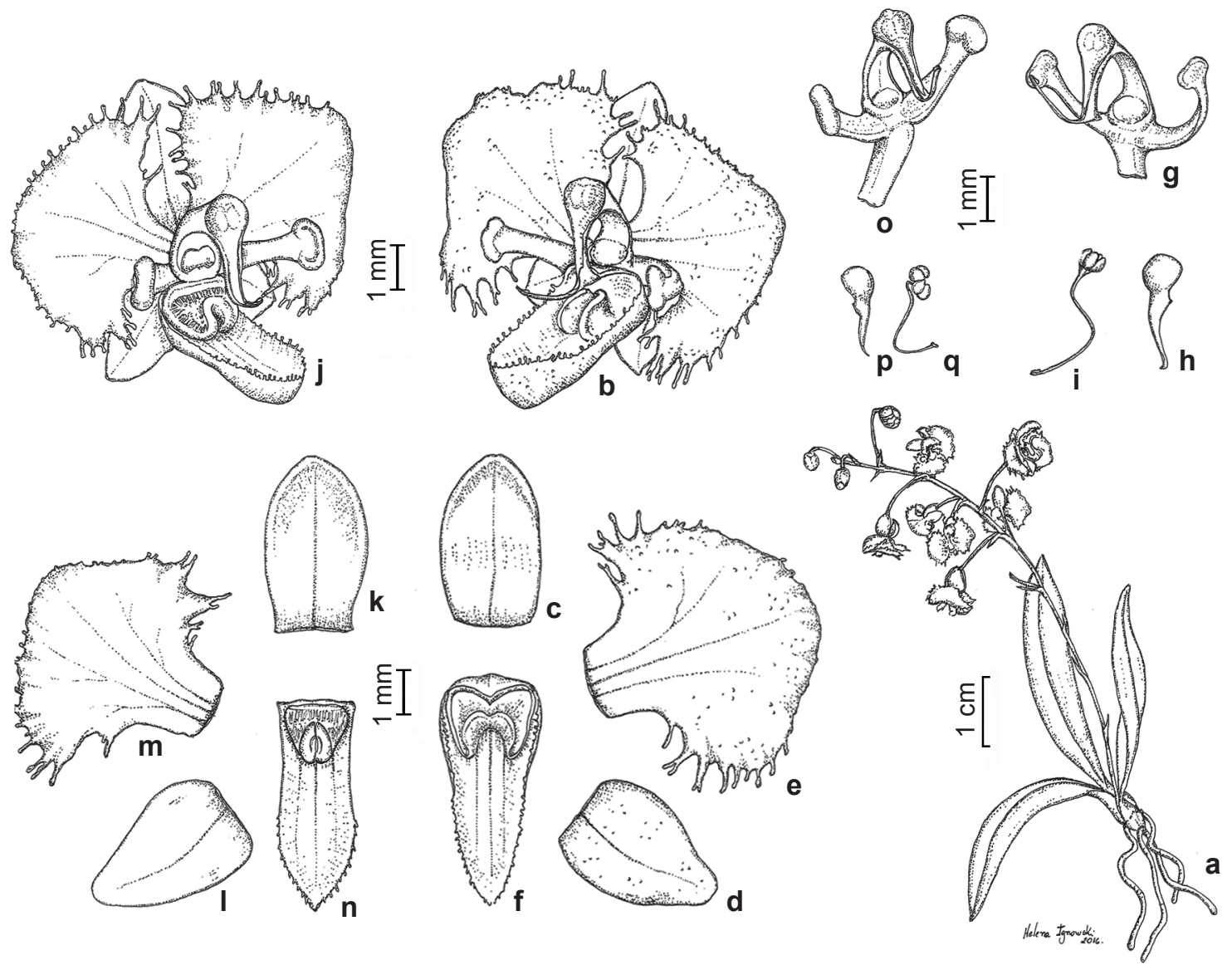

Figura 3 - a-i. Zygostates lunata - a. hábito; b. flor; c. sépala dorsal, vista frontal; d. sépala lateral, vista frontal; e. pétala, vista frontal; f. labelo, vista frontal; g. coluna, vista frontal; h. capa da antera, vista lateral; i. polinário, vista lateral. j,k. Z. cornuta - j. flor; k. sépala dorsal, vista frontal; 1 . sépala lateral, vista frontal; m. pétala, vista frontal; $n$. labelo, vista frontal; o. coluna, vista frontal; p. antera, vista lateral; q. polinário, vista lateral. (a-i. M. Borgo et al. 590; q. E. C. Smidt 972).

Figure 3 - a-i. Zygostates lunata - a. habit; b. flower; c. dorsal sepal, frontal view; d. lateral sepal, frontal view; e. petal, frontal view; f. lip, frontal view; g. column, frontal view; h. anther, lateral view; i. pollinarium, lateral view. j-q. Z. cornuta - j. flower; k. dorsal sepal, frontal view; 1. lateral sepal, frontal view; m. petal, frontal view; $\mathrm{n}$. lip, frontal view; o. column, frontal view; p. anther, lateral view; q. pollinarium, lateral view. (a-i. M. Borgo et al. 590; q. E.C. Smidt 972). 
1.4. Zygostates dasyrhiza (Kräenzl.) Schltr. Repert. Spec. Nov. Regni Veg 16: 449. 1920.

= Ornithocephalus dasyrhizus Kräenzl. Kongl. Svenska Vetensk. Acad. Handl., n.s. 46(10): 77. 1911. $=$ Zygostates paranaenses Schltr. Repert. Spec. Nov. Regni Veg. 22: 68. 1926.

Fig. 4a-j

Planta 26,5-54,4 mm alt., pendente ou ereta. Raízes dispersas, pilosas, distribuídas ao longo de um caule alongado, ramificado, folioso, com até ca. $35 \mathrm{~mm}$ de compr. Pseudobulbos 2,6-4,7 × 0,9-1,4 mm, unifoliados, papilosos, fusiformes, lateralmente sulcados, esparsos, parcialmente cobertos pelas bainhas das folhas laterais. Folhas laterais 9,2-19,8 × 2,2-4,6 mm, verde-acizentadas, carnosas, lanceoladas, papilosas, abaxialmente quilhadas, sulcadas adaxialmente, torcidas, ápice agudo. Folhas apicais similares às laterais, 10,1-18,6 $\times 2,6-4,6 \mathrm{~mm}$. Inflorescência 17,4-36 mm compr., ereta ou arqueada; brácteas $0,9-1,7 \times 0,4-1 \mathrm{~mm}$, laxas, ovadas a lanceoladas, glabras, côncavas. Flores simétricas, geralmente ressupinadas. Sépala dorsal 2,5-3,6 × 1-1,4 mm, branca, reflexa, oblonga a espatulada, côncava, abaxialmente quilhada, ápice obtuso, margens inteiras. Sépalas laterais 2,5-3 × 1,2-1,5 mm, brancas, patentes, elípticas ou oblongas, falciformes, côncavas, abaxialmente quilhadas, ápice obtuso, margens inteiras. Pétalas 3-3,4 $\times 2-2,6 \mathrm{~mm}$, brancas, patentes, obovadas a espatuladas, planas, glabras, ápice obtuso, margens levemente irregulares. Labelo 1,8-4,4 $\times$ 2,2-3,8 $\mathrm{mm}$, branco, patente, ovado-lanceolado, côncavo, abaxialmente quilhado, ápice acuminado e inflexo, margens levemente irregulares; disco com calosidade branca, arredondada, convexa, glandular-tricomatosa. Coluna 2-2,5 mm compr., levemente sigmóide, provida de dois apêndices laterais auriculados, patentes, obtusos, brancos; cavidade estigmática conspícua, oblonga à ovada; rostelo curvado para cima; ápice da coluna com margem fortemente dentada ou lacerada; antera com âmbito claviforme, longo-rostrada, acuminada, as margens laterais providas de um dente inconspícuo em cada lado próximo à região mediana; polinário com viscídio ovado.

Material examinado: Balsa Nova, Serra São Luiz, 6.I.1971, fl., G. Hatschbach 25945 (HB, K, MBM). Campo Largo, Ferraria, XI.1960, fl., M. Leinig 224 (HB). Curitiba, Capão Boi, Restinga Seca, 11.XII.1909, fl., Dusén 9863 (S); 28.XI.1944, fl., A. Guimarães (RB 260431); Parque Barigui, 19.XII.1995, fl., C. Kozera \& V.A. Dittrich 29 (UPCB); Bosque Jardim Saturno, 13.I.2001, f1., M. Borgo 1130 (UPCB). Guaratuba, Estrada Curitiba-Joinville, 20.III.1949, fl., G. Hatschbach 1251 (MBM). Mandirituba, 2.I.1964, fl., G. Hatschbach
10872 (HB, MBM). Próximo a Piraí do Sul, 16.X.1972, fl., A. Seidel 1046 (HB). Piraquara, Rio São Jerônimo, 20.III.2003, fl., R. Kersten et al. 608 (UPCB); Haras Santo Antônio, 15.I.2004, fl., R. Kersten 766 (UPCB). Ponta Grossa, Passo do Pupo, 4.XII.1967, fl., G. Hatschbach 17999 (HB, MBM); Parque Estadual de Vila Velha, Mata da Fortaleza, 3.XII.2014, fl., J.M. Silva \& J.T. Motta 8700 (UPCB). São José dos Pinhais, Rincão, 22.I.1950, fl., G. Hatschbach 1784 (MBM, SP); cultivado em orquidário, 17.XII.2014, fl., C.A. Royer 38 (UPCB). Serrinha, 9.XII.1908, P.K.H. Dusén 7333 (AMES, HB, NY, S); I.1910, fl., P.K.H. Dusén 9039 (S). Tijucas do Sul, Matulão, I.I.1964, fl., G. Hatschbach 10870 (B, HB, MBM); Ambrósios, 10.I.1992, fl., O.S. Ribas \& J. Cordeiro 398 (MBM); Fazenda São Benedito, 4.XII.2015, fl., C.A. Royer \& D.C. Imig 90 (UPCB). Tunas do Paraná, Parque Estadual de Campinhos, 19.II.1999, fl., J.M. Silva \& L.M. Abe 2882 (HRCB, MBM). S. loc., s.d., fl., F. Lange 9863 (HB, MBM).

Zygostates dasyrhiza é encontrada no Litoral, Serra do Mar, Primeiro e Segundo Planaltos, habitando as Florestas Ombrófilas Densa e Mista e a Estepe Gramíneo Lenhosa. No Brasil ocorre somente nos três estados do Sul (Royer et al. 2017).

Segundo os critérios da IUCN (2001), a espécie enquadra-se na categoria "Vulnerável" (VU; $\mathrm{B} 1 \mathrm{~b}(\mathrm{i}, \mathrm{ii}))$ devido à restrita área de ocorrência $(\mathrm{EOO})$ e ocupação (AOO), apesar de ser encontrada em 11 localidades e em dois parques estaduais (PE): PE Campinhos e PE Vila Velha.

Em seu hábito usualmente reptante e pendente, Zygostates dasyrhiza assemelha-se à Z . pustulata. Distingui-se dessa, porém, pelo labelo marcadamente acuminado, pela coluna simétrica e pela margem dentada ou lacerada do ápice da coluna. Floresce de dezembro a março.

1.5. Zygostates lunata Lindl. Edwards's Bot. Reg. 23: sub t.1927. 1837.

= Dactylostylis fimbriata Scheidw. Allg. Gartenzeitung. 7: 406. 1839.

$=$ Epidendrum trilabiatum Vell. Fl. Flum. 9: t. 42. 1831.

= Ornithocephalus navicularis Barb.Rodr. Gen. Sp. Orchid. 1: 135. 1877. Fig. 3a-i

Planta 90-162 mm alt., pendente. Raízes cespitosas, glabras. Pseudobulbos 3,8-7,2 × 1,3-2,2 $\mathrm{mm}$, unifoliados, glabros, ovoides a elipsoides, lateralmente sulcados, congestos, parcialmente cobertos pelas bainhas das folhas laterais. Folhas laterais 45,2-85,2 ×6,5-13 mm, verdes, coriáceas, lanceoladas, espatuladas ou elípticas, glabras, abaxialmente quilhadas e um pouco torcidas, ápice agudo a obtuso. Folhas apicais similares às laterais, 34,7-85,4 × 4,4-10,1 mm. Inflorescência 67,8-155 
mm compr., arqueada; brácteas $1,3-4,7 \times 0,7-1,4$ $\mathrm{mm}$, laxas, lanceoladas, ovadas a triangulares, glabras, côncavas. Flores simétricas, ressupinadas. Sépala dorsal 2,4-3,2 × 1,3-2 mm, brancas a esverdeadas, reflexa, elíptica, convexa, abaxialmente quilhada, às vezes levemente conada com as sépalas laterais na base, ápice obtuso, margens levemente irregulares. Sépalas laterais 2,4-3,3 × 1,5-2,2 mm, brancas a esverdeadas, reflexas, ovadas, falciformes, convexas, abaxialmente quilhadas, conadas na base, ápice obtuso, margens inteiras. Pétalas 2,5-3,7 $\times 2,9-4,2 \mathrm{~mm}$, alaranjadas, patentes a um pouco

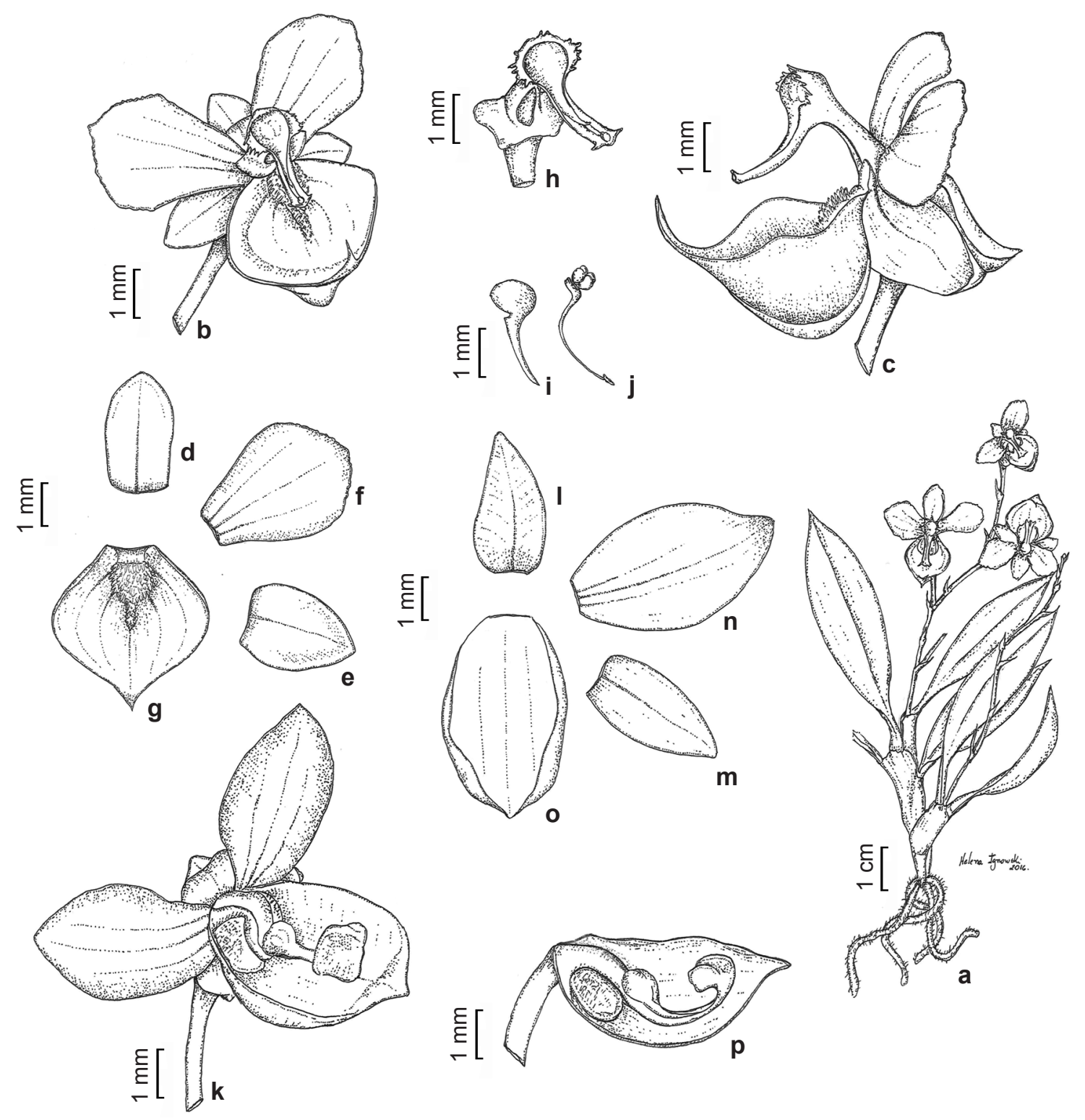

Figura 4 -a-j. Zygostates dasyrhiza - a. hábito; b. flor; c. flor, vista lateral; d. sépala dorsal, vista frontal; e. sépala lateral, vista frontal; f. pétala, vista frontal; g. labelo, vista frontal; h. coluna, vista frontal; i. antera, vista lateral; j. polinário, vista lateral. k-p. Z. pustulata - k. flor; 1. sépala dorsal, vista frontal; m. sépala lateral, vista frontal; n. pétala, vista frontal; o. labelo, vista frontal; p. labelo e coluna em vista lateral, o labelo em secção longitudinal. (a-j. C.A. Royer \& D.C. Imig 90; k-p. E.F. Costa et al. 35). Figure 4 - a-j. Zygostates dasyrhiza - a. habit; b. flower; c. flower, lateral view; d. dorsal sepal, frontal view; e. lateral sepal, frontal view; $\mathrm{p}$. petal, frontal view; g. lip, frontal view; h. column, frontal view; i. anther, lateral view; j. pollinarium, lateral view. k-p. Z. pustulata - k. flower; 1 . dorsal sepal, frontal view; $\mathrm{m}$. lateral sepal, frontal view; $\mathrm{n}$. petal, frontal view; $\mathrm{o}$. lip, frontal view; $\mathrm{p}$. lip and column, lateral view, lip longitudinally sectioned. (a-j. C.A. Royer \& D.C. Imig 90; k-p. E.F. Costa et al. 35). 
eretas, unguiculadas, reflexas em direção ao ápice, planas, glabras, ápice obtuso, margens fimbriadas. Labelo 2,8-3,9 × 1,4-2,2 mm, branco, inflexo, ovado, côncavo, ápice agudo, margens dentadas ou fimbriadas; disco com calosidade amarelo-marrom, côncava, glandular-tricomatosa, apiculada na base, bilobada no ápice. Coluna 1,7-2,5 mm compr., sigmóide, provida na base de dois apêndices laterais claviformes, alaranjados; cavidade estigmática conspícua, ovada à elíptica; rostelo reflexo, provido abaxialmente de uma aba ou membrana truncada, às vezes levemente crenada ou bilobada; ápice da coluna com margem inteira; antera operculada, mais curta do que o rostelo, longo-rostratada, acuminada, as margens laterais providas de um dente inconspicuo em cada lado próximo à região mediana; polinário com viscídio elíptico.

Material examinado: Mauá da Serra, 23.XII.2009, fl., M.A. Guttiere 64 (HUEM). Monte Alegre, XI.1959, fl., F. Feigl in M. Leinig 161 (HB). Telêmaco Borba, 28.XI.2007, fl., A. Bonnet 580105 (UPCB); XII.2011, fl., V. Ariati 567 (MBM); Área de alagamento da UHE Mauá, 2.II.2012, fl., M.A. Milaneze-Gutierre (HUEM 22249); 7.XII.2012, fl., C. Michelon 1603 (MBM); Área de alagamento da UHE Mauá, 23.X.2013, fl., M.A. Milaneze-Gutierre et al. (HUEM 24240). Tibagi, Jaguatirica - Fazenda Monte Alegre, 15.XII.1952, fl., G. Hatschbach 2859 (MBM). Sapopema, Fazenda Guaporé, Rio Tibagi, 9.XII.1995, fl., L.H. Soares et al. (FUEL 17003). S. loc., 5.IV.1911, fl., F. Lange (MBM 215509).

Zygostates lunata ocorre somente no Segundo Planalto, na Floresta Ombrófila Mista e na Estepe Gramíneo Lenhosa. Ocorre também nos estados de São Paulo e Rio de Janeiro (Royer et al. 2017).

Segundo critérios da IUCN (2001), esta espécie deve ser enquadrada na categoria "Espécie em Perigo" (EN; Blb(i,ii)), pois é encontrada em apenas cinco localidades no estado e sua área de ocorrência (EOO) e ocupação (AOO) são reduzidas. Além disso, não há registro para unidades de conservação e os locais indicados nos materiais testemunhos indicam uma área atualmente alagada pela barragem da Usina Hidrelétrica Mauá da Serra.

Zygostates lunata assemelha-se muito à Z. cornuta, mas difere dessa pela morfologia da calosidade do labelo, sobretudo o prolongamento apiculado em sua base e pela presença de uma membrana localizada na face abaxial da coluna, mais ou menos na região mediana do rostelo. Floresce entre outubro e abril.
1.6. Zygostates multiflora (Rolfe) Schltr. Arch. Bot. São Paulo. 1: 295. 1926.

= Ornithocephalus multiflorus Rolfe Bull. Misc. Inform. Kew. 149. 1901.

= Dipteranthus multiflorus (Rolfe) I.Bock \& Seehawer. Orchidee (Hamburg). 47: 282. 1996.

Fig. 1i-o

Planta 66-118 mm alt., ereta. Raízes cespitosas, glabras. Caule 7,8-11 mm compr. Pseudobulbos 5,1-5,6 × 2,4-2,6 mm, uni ou bifoliados, glabros, ovoides, lisos, congestos, parcialmente cobertos pelas bainhas das folhas laterais. Folhas laterais 25,6-34,4 × 3,3-4 mm, verdes, coriáceas, lanceoladas, espatuladas ou elípticas, glabras, ápice agudo. Folhas apicais similares às laterais, 22,7-36,3 × 4-4,8 mm. Inflorescência 60-107 mm compr., arqueada; brácteas $2-3,4 \times 0,6-1,2 \mathrm{~mm}$, congestas, ovadas a triangulares, glabras, côncavas, abaxialmente quilhadas. Flores simétricas, ressupinadas. Sépala dorsal 1,7-2,1 × 0,5-0,8 mm, branca, reflexa, elíptica, côncava, abaxialmente quilhada, levemente conada na base com as sépalas laterais, ápice agudo a obtuso, margens inteiras. Sépalas laterais $1,5-1,8 \times 0,7-1,2 \mathrm{~mm}$, brancas, reflexas, ovadas, falciformes, côncavas, conadas na base, ápice agudo, margens inteiras. Pétalas $2-2,8 \times$ 2,1-2,5 mm, brancas, patentes, unguiculadas, levemente convexas, glabras, ápice obtuso, margens levemente irregulares. Labelo 2,4-4 × 1-1,4 mm, branco, patente, bilobado na base, giboso na região mediana, levemente panduriforme quando explanado, côncavo, ápice agudo, margens inteiras; disco com calosidade branca, carnosa, arredondada, côncava, glandular-tricomatosa, com ápice verde, emarginado e recurvado. Coluna 1,22,1 mm compr., levemente sigmoide, geniculada mais ou menos no meio, provida na base por dois apêndices laterais eretos, triangulares, brancos; cavidade estigmática conspícua, ovada; rostelo projetado para frente; ápice da coluna com margem inteira; antera claviforme, as margens laterais providas de um dente insconspícuo em cada lado próximo à região mediana; polinário com viscídio arredondado.

Material examinado: Morretes, Serra Marumbi, 19.I.1971, fl., G. Hatschbach 25991 (C, HB, MBM, S); Véu da Noiva, 5.V.1986, fl., J. Cordeiro \& J.M. Silva 234 (MBM).

Até o presente, Zygostates multiflora é conhecida somente para a Serra do Mar, habitando a Floresta Ombrófila Densa. Ocorre também nos estados de São Paulo e do Rio de Janeiro (Royer et al. 2017). 
Segundo os critérios da IUCN (2001), a espécie é considerada "Criticamente em Perigo" (CR; $\mathrm{B} 1 \mathrm{~b}(\mathrm{i}, \mathrm{ii})$ ), uma vez que possui apenas dois registros de coleta, ambos para o município de Morretes, sendo um deles para o Parque Estadual do Pico Marumbi.

Zygostates multiflora se caracteriza pelo labelo levemente panduriforme e giboso, pela calosidade do labelo arredondada e carnosa, e pela coluna geniculada, provida na base de dois apêndices laterais conspícuos, eretos e triangulares. Floresce de janeiro a maio.

1.7. Zygostates pellucida Rchb.f Ann. Bot. Syst. 6: 564 (1863).

$=$ Dipteranthus pellucidus (Rchb.f.) Cogn. Fl. Brasil. 3(6): 214. 1905.

= Ornithocephalus pseudobulbifer Barb.Rodr. Gen. Spec. Orchid. Nov. 1: 134 (1877).

= Dipteranthus pseudobulbifer (Barb.Rodr.) Barb. Rodr. Gen. Spec. Orchid. Nov. 2: 233 (1882).

Fig. 5a-g

Planta $38-100 \mathrm{~mm}$ alt., pendente ou às vezes ereta. Raízes cespitosas, pilosas. Pseudobulbos $6,3-12 \times 2,5-5,7 \mathrm{~mm}$, unifoliados, papilosos, ovoides, lateralmente sulcados, congestos, parcialmente cobertos pelas bainhas das folhas laterais. Folhas laterais $25-53 \times 9,3-11,6 \mathrm{~mm}$, se presentes, verdeescuras, coriáceas, ovadas a elípticas, minimamente papilosas e um pouco torcidas na base, ápice agudo. Folhas apicais similares às laterais, 34,9-89,1 $\times$ 9,1-16 mm. Inflorescência 22,4-86,4 mm compr., arqueada; brácteas 1,9-3,9 × 0,9-1,6 mm, laxas, lanceoladas a ovadas, papilosas, côncavas. Flores simétricas, ressupinadas. Sépala dorsal 3,9-4,7× 1,72,2 mm, branca, reflexa, linear ou elíptica, convexa, abaxialmente quilhada, ápice obtuso, margens inteiras. Sépalas laterais 3,9-4,5 × 1,7-2,3 mm, brancas, reflexas, obovadas, falciformes, côncavas, ápice obtuso, margens inteiras. Pétalas 4,8-5,4 $\times$ 1,6-2,7 mm, verdes, inflexas, espatuladas, convexas, papilosas, densamente glandular-tricomatosas na face adaxial, fortemente convexas, às vezes quase tubulares, projetadas para a frente e para baixo, ápice agudo ou obtuso, margens inteiras. Labelo 3,4-5,1 × 1,4-1,7 mm, verde, patente, bilobado na base, panduriforme, côncavo, ápice agudo, margens levemente irregulares; disco com calosidade verde, oblonga, côncava, glandular-tricomatosa, com ápice truncado e reflexo. Coluna 2,9-3,1 mm compr., geniculada, bruscamente curvada para frente, provida na base por dois apêndices laterais eretos, espatulados, verdes; cavidade estigmática conspícua, arredondada; rostelo projetado para frente e para cima; ápice da coluna com margem inteira; antera ovada, as margens laterais providas de um dente inconspícuo em cada lado próximo a região mediana; polinário com viscídio ovado.

Material adicional examinado: BRASIL. SANTA CATARINA: Florianópolis, Morro do Ribeirão, 14.II.1967, fl., R.M. Klein 7173 (FLOR); Morro do Rio Vermelho, 11.II.1969, fl., R.M. Klein \& A. Bresolin 8217 (FLOR); Morro Costa da Lagoa, 13.XI.1969, fl., R.M. Klein 8213 (FLOR); Morro do Ribeirão, 14.II.1969, fl., R.M. Klein 8213 (FLOR); Pântano do Sul, 21.I.1971, fl., A. Bresolin 133 (FLOR); Vargem Grande, 20.II.1974, fl., A. Bresolin 1121 (FLOR). Joinville, Morro da Tromba, 14.I.2008, fl., W. Mancinelli 821 (JOI). Palhoça, Morro do Cambirela, 23.II.1972, fl., R.M. Klein \& A. Bresolin 10074 (FLOR); Praia da Ponta do Papagaio, 8.I.2016, fl., C.A. Royer 95 (UPCB). Paulo Lopes, Bom Retiro, 19.XI.1973, fl., R.M. Klein \& A. Bresolin 10833 (FLOR). SÃO PAULO: Caraguatatuba, 13.I.2016, fl., C.A. Royer \& M. Rodrigues 96 (UPCB).

Zygostates pellucida possui registro somente para o litoral paranaense (Blum et al. 2011). Apesar do espécime citado em Blum et al. (2011) não ter sido localizado, a espécie é bem distribuída nos demais estados do sul e sudeste do Brasil, ocorrendo no Rio Grande do Sul, Santa Catarina, São Paulo, Rio de Janeiro e Espírito Santo (Royer et al. 2017). A descrição e ilustração aqui fornecidos baseiam-se em C.A. Royer 95 (UPCB).

Segundo os critérios da IUCN (2001), Z. pellucida deve ser enquadrada na categoria "Criticamente em Perigo" (CR; B1b(i,ii)). Ainda que coletada em unidade de conservação, a espécie possui somente um registro para o estado.

Zygostates pellucida pode ser reconhecida através da forma das pétalas distintamente glandulartricomatosas, curvadas para frente e fortemente convexas, pelo labelo panduriforme, e pela coluna geniculada e bruscamente curvada para a frente. Floresce de novembro a fevereiro.

1.8. Zygostates pustulata (Kräenzl.) Schltr. Repert. Spec. Nov. Regni Veg. 22: 69. 1926.

= Ornithocephalus pustulatus Kräenzl. Kongl. Svenska Vetensk. Acad. Handl., n.s. 46(10): 77. 1911. = Dipteranthus pustulatus (Kräenzl.) Pabst, Orquídea (Rio de Janeiro) 28(3): 167. 1966.

= Ornithocephalus dusenianus Kräenzl. Ark. Bot. 16(8): 26. 1921.

= Zygostates duseniana (Kräenzl.) Pabst Arch. Jard. Bot. Rio de Janeiro. 14: 27. $1956 . \quad$ Fig. 4k-p

Planta 76,1-120 mm alt., pendente ou às vezes ereta. Raízes dispersas, glabras, distribuídas ao longo de um caule alongado, ramificado, folioso, de até ca. $70 \mathrm{~mm}$ de compr. Pseudobulbos 2,8-5 
$\times 0,7-1,4 \mathrm{~mm}$, unifoliados, glabros, elipsoides, lisos, esparsos, parcialmente cobertos pelas bainhas das folhas laterais. Folhas laterais $25,6-40,4$ $\times 2,3-2,7 \mathrm{~mm}$, verde-acizentadas, carnosas, lanceoladas a espatuladas, glabras, abaxialmente quilhadas, sulcadas adaxialmente, torcidas, ápice acuminado. Folhas apicais similares às laterais, 21,1-33,2 × 1,9-3,1 mm. Inflorescência 38,3-63 $\mathrm{mm}$ compr., ereta ou arqueada; brácteas $1,6-5 \times$ 0,4-1,1 mm, laxas, ovadas a lanceoladas, glabras, côncavas, abaxialmente quilhadas. Flores simétricas, geralmente não-ressupinadas. Sépala dorsal 2,4-2,8 $\times 1-1,4 \mathrm{~mm}$, branca, reflexa, ovada à elíptica, ligeiramente côncava, abaxialmente quilhada, ápice agudo, margens inteiras. Sépalas laterais 1,9-2,8 × 1,1-1,4 mm, brancas, reflexas, obliquas, ligeiramente côncavas, ápice agudo, margens inteiras. Pétalas 3,8-4,7 × 2,3-2,5 $\mathrm{mm}$, brancas, patentes, elípticas, planas, glabras, abaxialmente quilhadas, ápice agudo a obtuso, margens inteiras. Labelo 3,6-4,6 × 2,3-3,1 mm, branco, patente, ovado, côncavo, abaxialmente quilhado, ápice agudo a obtuso, margens inteiras; disco com calosidade verde, subquadrada, côncava, glandulartricomatosa, bilobada no ápice. Coluna 2,3-3,4 mm compr., fortemente curvada para frente e fundida com o calo presente na base do labelo, desprovida de apêndices; cavidade estigmática inconspícua; rostelo adaxialmente caniculado, curvado para cima, paralelo à curvatura do labelo, assimétrico, o ápice dilatado, distintamente entumescido e torcido; ápice da coluna com margem inteira; antera ovada,

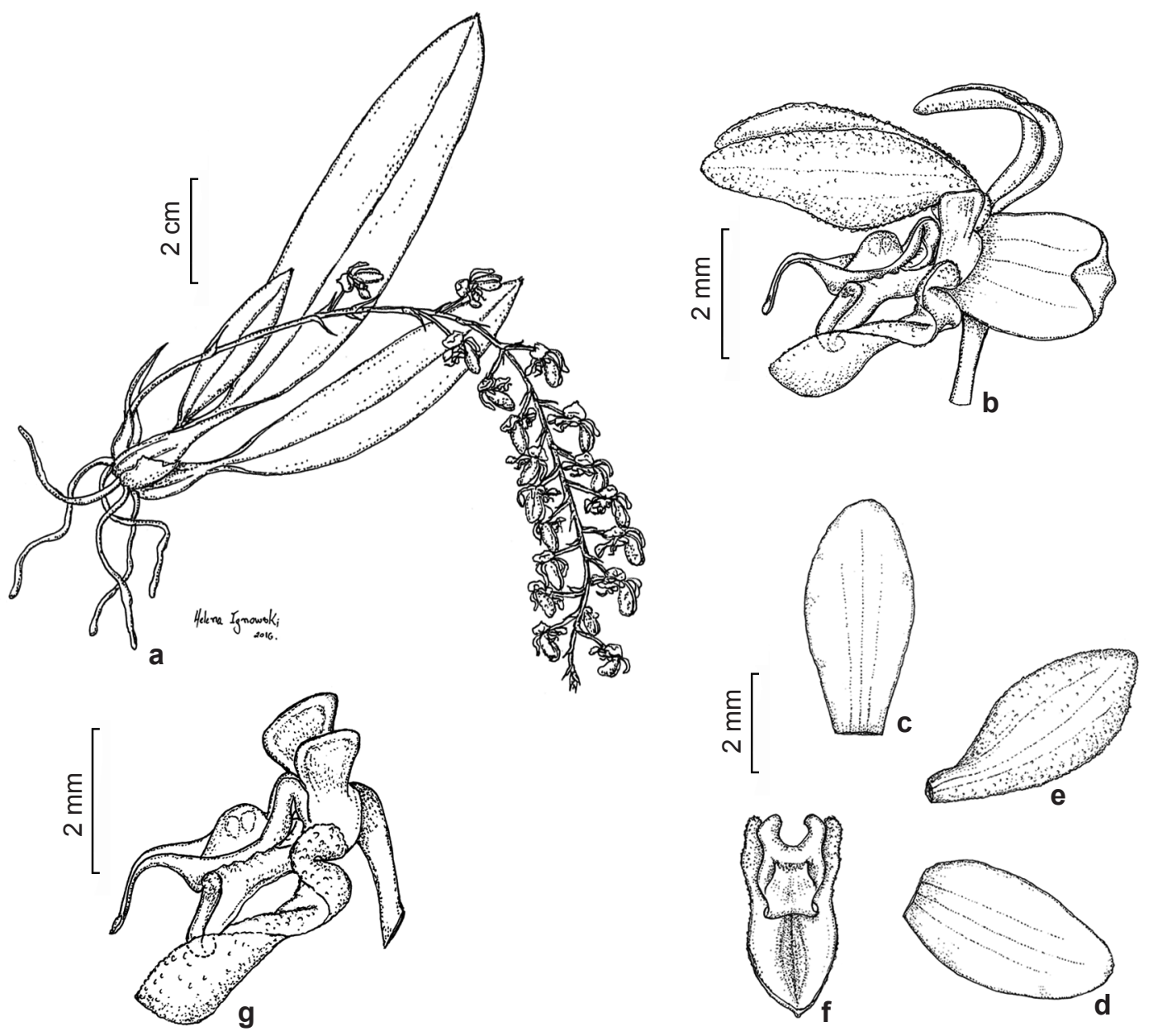

Figura 5 - a-g. Zygostates pellucida - a. hábito; b. flor; c. sépala dorsal, vista frontal; d. sépala lateral, vista frontal; e. pétala, vista frontal; f. labelo, vista frontal; g. coluna com labelo, vista lateral (C.A. Royer 95).

Figure 5 - a-g. Zygostates pellucida - a. habit; b. flower; c. dorsal sepal, frontal view; d. lateral sepal, frontal view; e. petal, frontal view; f. lip, frontal view; g. column with lip, lateral view (C.A. Royer 95). 


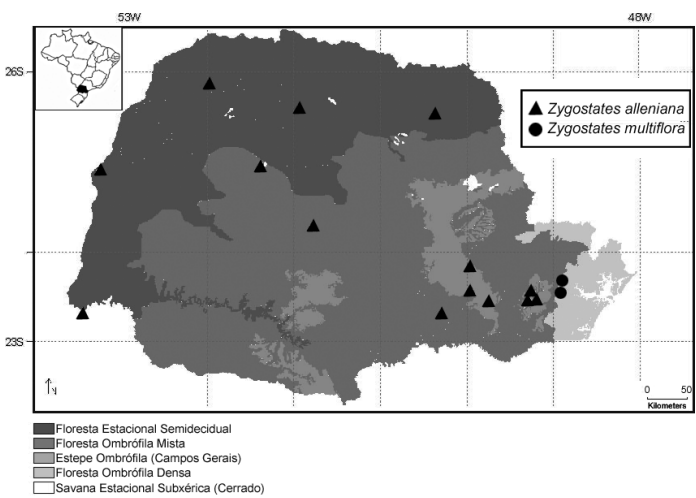

Figura 6 - Distribuição de Zygostates alleniana e Zygostates multiflora no Paraná.

Figure 6 - Distribution of Zygostates alleniana and Zygostates multiflora in Paraná.

brevemente rostrada, as margens inteiras; polinário com víscidio ovado, inserido numa depressão lateral na região apical do rostelo.

Material examinado: Campina Grande do Sul, Serra Ibitiraquire, 10.IV.2006, fl., O.S. Ribas et al. 7175 (MBM). Corumbataí do Sul, Córrego Palmital, 14.III.2008, fl., H.C.L. Geraldino 492 (HCF). Morretes, Pico Marumbi, Serra do Mar, 22.II.1962, fl., M. Leinig 280 (HB); Estrada da Graciosa, Alto da Serra 16.IV.1975, fl., G. Hatschbach 36642 (HB, MBM); Parque Estadual do Pico Marumbi, 20.IV.1998, fl., C. Giongo 40 (UPCB); 25.III.1999, fl., C. Giongo et al. 139 (UPCB); 27.II.2001, fl., M.P. Petean 162 (UPCB); Serra Marumbi, 22.II.2005, fl., E.F. Costa et al. 35 (MBM); Serra da Prata, 9.XI.2009, fr., C.T. Blum \& M.L. Brotto 659 (EFC); Serra da Farinha Seca, Morro Mãe Catira, 21.IV.2014, fl., C.T. Blum 1603 (EFC); 30.III.2015, fl., T.F. Santos \& R. Kersten 76 (UPCB). Piraquara, Roça Nova, Serra do Mar, 18.II.1911, fl., Dusén 11608 (S);

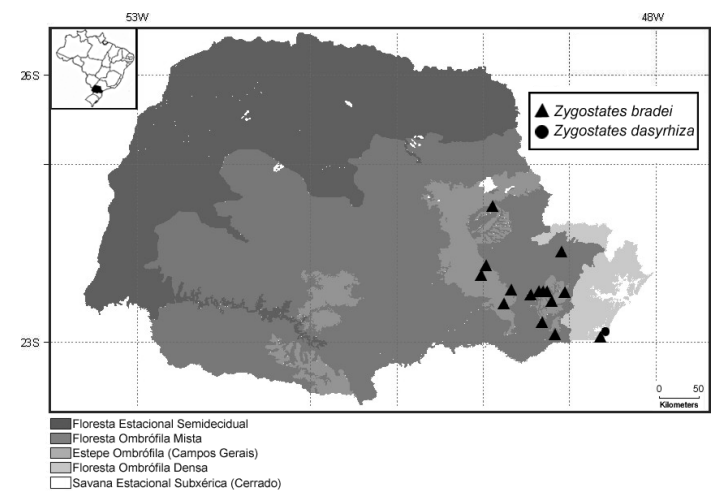

Figura 7 - Distribuição de Zygostates bradei e Zygostates dasyrhiza no Paraná.

Figure 7 - Distribution of Zygostates bradei and Zygostates dasyrhiza in Paraná.

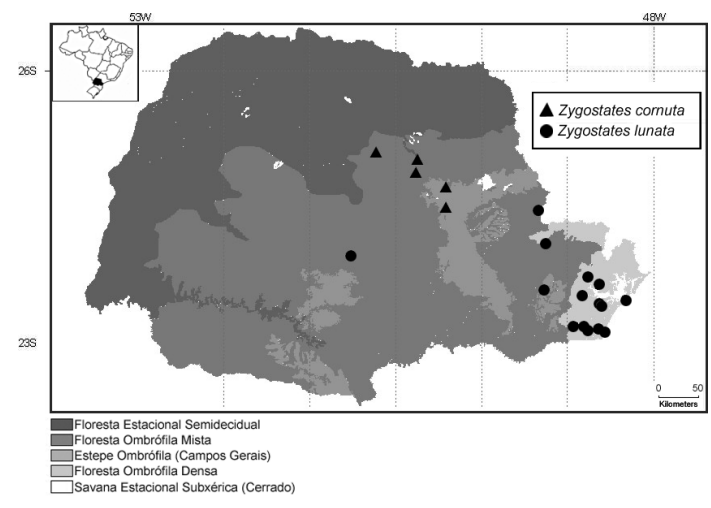

Figura 8 - Distribuição de Zygostates cornuta e Zygostates lunata no Paraná.

Figure 8 - Distribution of Zygostates cornuta and Zygostates lunata in Paraná.

Morro Anhangava, 8.IV.1951, fl., G. Hatschbach 2212 (HB, MBM, PACA, SP). Quatro Barras, Casa Ypiranga em Silva prim., 2.IV.1910, fl., F. Lange $9856=1184=11392$ (HB); 18.III.1916, fl., P.K.H. Dusén 18029 (S); Rio do Corvo, 1.IV.1969, fl., G. Hatschbach 21308 (HB, MBM); Morro Mãe Catira, 9.IV.1986, fl., J. Cordeiro \& A. Manosso 279 (MBM).

Zygostates pustulata é encontrada no Litoral, Serra do Mar e Primeiro Planalto, habitando a Floresta Ombrófila Densa. Ocorre também no estado de Santa Catarina (Royer et al. 2017).

Segundo os critérios da IUCN (2001), a espécie é considerada "Vulnerável” (VU; B1b(i,ii)), pois ocorre em apenas seis localidades no estado e possui área de ocorrência (EOO) e ocupação (AOO) reduzidas. Além disso, não é encontrada em Unidades de Conservação no Paraná.

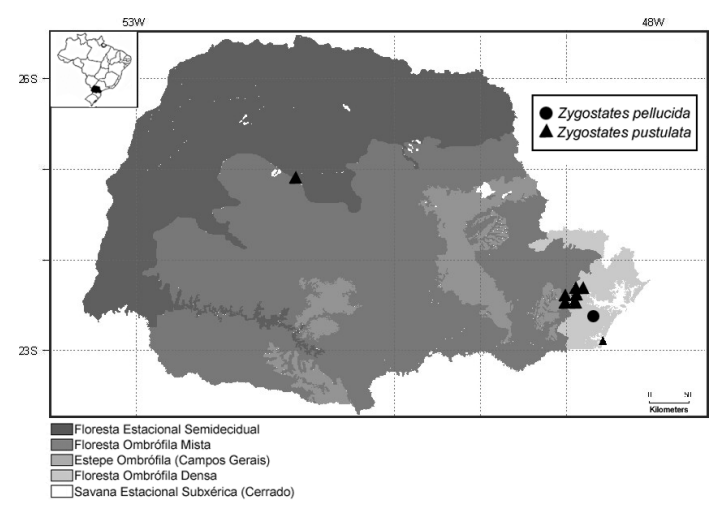

Figura 9 - Distribuição de Zygostates pellucida e Zygostates pustulata no Paraná.

Figure 9 - Distribution of Zygostates pellucida and Zygostates pustulata in Paraná. 
Zygostates pustulata possui hábito semelhante à $Z$. dasyrhiza, mas difere dessa por possuir raízes glabras. A coloração das flores também é semelhante nas duas espécies, mas $Z$. pustulata é facilmente reconhecida pelas pétalas bem maiores que as sépalas e o rostelo torcido e entumescido no ápice. Floresce de fevereiro a abril.

\section{Agradecimentos}

Os autores agradecem aos curadores dos herbários aqui citados, o empréstimo dos materiais; ao Marie Selby Botanical Gardens, o apoio financeiro para a confecção dos desenhos a nanquin; a Helena Ignowski, a realização das ilustrações. Somos gratos também ao Dr. Wade Collier, a ajuda na montagem das estampas. C.A.R. agradece à CAPES, a bolsa de Doutorado concedida; ao IAP ( $\left.\mathrm{N}^{\circ} 32.15\right)$ e ao ICMBio (SISBIO - 30642-1), as autorizações de coletas. E.C.S. agradece ao Conselho Nacional de Desenvolvimento Científico e Tecnológico (CNPq), a bolsa de Produtividade em Pesquisa do CNPq-Nível 2 (proc. 311001/2014-9) e ao MCTI/CNPq No 14/2013 - Universal (proc. 485396/2013-0). A.L.V.T.B. agradece à CAPES, a bolsa Programa Pesquisador Visitante Especial (PVE), 88881.065009/2014-0.

\section{Referências}

Bachman S, Moat J, Hill AW, De La Torre J \& Scott B (2011) Supporting red list threat assessments with GeoCAT: geospatial conservation assessment tool. In: Smith V \& Penev L (eds.) e-Infratructures for data publishing in biodiversity science. Zookeys 150: 117-126.

BFG - The Brazil Flora Group (2015) Growing knowledge: an overview of seed plant diversity in Brazil. Rodriguésia 66: 1085-1113.

Blum CT, Roderjan CV \& Galvão F (2011) Composição florística e distribuição altitudinal de epífitas vasculares da Floresta Ombrófila Densa na Serra da Prata, Morretes, Paraná, Brasil. Biota Neotropica 11: 141-159.

Chase MW \& Toscano de Brito ALV (2009) Zygostates. In: Pridgeon AM, Cribb PJ, Chase MW \& Rasmussen F (orgs.) Genera Orchidacearum. Epidendroideae (Part 2). Vol. 5. Oxford University Press Inc., New York. Pp. 391-394.

Chase MW, Cameron KM, Freudenstein JV, Pridgeon AM, Salazar G, van den Berg C \& Schuiteman A (2015) An uptaded classification of Orchidaceae. Botanical Journal of the Linnean Society 177: 151-174.

Dallwitz MJ, Paine TA \& Zurcher EJ (2011) DELTA Editor: description language for taxonomy. Disponível em $<$ http://delta-intkey.com $>$. Acesso em 16 fevereiro 2016.

Gonçalves EG \& Lorenzi H (2011) Morfologia vegetal: organografia e dicionário ilustrado de morfologia das plantas vasculares. $2^{\text {a }}$ ed. Instituto Plantarum de Estudos da Flora, Nova Odessa. 512p.

Harris JG \& Harris MW (1994) Plant identification terminology: an illustrated glossary. Spring Lake Publishing, Spring Lake. 206p.

Hatschbach GG \& Ziller SR (1995) Lista vermelha de plantas ameaçadas de extinção no estado do Paraná. SEMA/GTZ, Curitiba. 139p.

Hijmans RJ, Guarino L, Bussink C, Mathur P, Cruz M, Barrentes I \& Rojas E (2012) DIVA-GIS: A geographic information system for the analysis of species distribution data. Versão 7.5. Disponível em $<$ http://www.diva-gis.org $>$. Acesso em 7 março 2016.

IUCN Standards and Petitions Subcommittee (2001) Guidelines for using the IUCN red list categories and criteria. Version 8.1. Prepared by the Standards and Petitions Subcommittee in March 2010. Disponível em $<$ http://jr.iucnredlist.org/documents/redlist_cats_ crit_en.pdf $>$. Acesso em 29 agosto 2016.

Johnson AE (2001) Las Orquídeas del Parque Nacional Iguazú. L.O.L.A., Buenos Aires. 296p.

Lange MBR (1997) Programa Guaraqueçaba - seis anos de atuação da Sociedade de Pesquisa em Vida Selvagem (SPVS) na Área de Proteção Ambiental de Guaraqueçaba, PR. In: Congresso Brasileiro de Unidades de Conservação. Vol. 2. IAP/UNILIVRE/ Rede Nacional Pró Unidades de Conservação, Curitiba. 911p.

Lindley J (1837) Burlingtónia cándida. Snow-white Burlingtonia. Edwards's Botanical Register 23: t. 1927.

Kräenzlin FWL (1911) Beiträge zur Orchideenflora Südamerikas. Kongliga Svenska Vetenskaps Academiens nya Handlingar 46: 1-105.

Maack R (1968) As zonas das paisagens naturais. In: Maack R. Geografia física do Paraná. BADEP, UFPR, Curitiba. 526p.

Pabst GFJ \& Dungs F (1977) Orchidaceae Brasilienses, Vol. 2. Brucke-Verlag Kurt Schmersow, Hildesheim. $418 \mathrm{p}$.

Roderjan CV, Kuniyoshi YS \& Galvão F (1993) As regiões fitogeográficas do estado do Paraná. Acta Forestalia Brasiliensis 1: 1-7.

Royer CA, Toscano de Brito ALV \& Smidt EC (2017) Zygostates. In: Flora do Brasil 2020 em construção. Jardim Botânico do Rio de Janeiro. Disponível em $<$ http://floradobrasil.jbrj.gov.br/reflora/floradobrasil/ FB12391>. Acesso em 6 setembro 2017.

Sambin A \& Chiron GR (2015) Premier enregistrement de Zygostates Lindley (Orchidaceae) en Guyane française. Richardiana 16: 51-56.

Smidt EC (2014) Orchidaceae. In: Kaehler M, Goldenberg R, Labiak PH, Ribas OS, Vieira AOS \& Hatschbach GG (eds.) Plantas vasculares do Paraná. Departamento de Botânica, Curitiba. Pp. 156.

Stern WT (2004) Botanical Latin. Timber Press, Portland. 546p. 
Thiers B [continuously updated] Index Herbariorum: the herbaria of the world. New York Botanical Garden. Disponível em <http://sweetgum.nybg.org/ih/>. Acesso em 9 março de 2016.

Toscano de Brito ALV (1994) Systematic studies in the subtribe Ornithocephalinae (Orchidaceae). Tese de Doutorado. Universidade de Reading e Royal Botanic Gardens, Kew. 652p.
Toscano de Brito ALV (2001) Systematic review of the Ornithocephalus group (Oncidiinae: Orchidaceae) with comments on Hofmeisterella. Lindleyana 16: 157-217.

Veloso HP, Rangel Filho ALR \& Lima JCA (1991) Classificação da vegetação brasileira adaptada a um sistema universal. IBGE/Projeto Radambrasil, Rio de Janeiro. 123p. 